\title{
Ambient Variable Pressure Field Emission Scanning Electron Microscopy for Trichome Profiling of Plectranthus tomentosa by Secondary Electron Imaging
}

\author{
Ki Woo Kim* \\ School of Ecology and Environmental System, Kyungpook National University, Sangju 742-711, Korea
}

*Correspondence to:

Kim KW,

Tel: +82-54-530-1246

Fax: +82-54-530-1248

E-mail: kiwoo@knu.ac.kr

Received January 29, 2013

Revised February 21, 2013

Accepted February 26, 2013
Glandular and nonglandular trichomes on the leaf surface of Plectranthus tomentosa were investigated by variable pressure field emission scanning electron microscopy (VPFESEM). The segments of the plant's leaves were directly mounted without any specimen preparation, and examined at ambient temperature using a variable pressure secondary electron (SE) detector under ca. $15 \mathrm{~Pa}$. Foliar trichomes maintained their shapes and structures without severe surface collapse or charging. The adaxial leaf surface was abundantly covered with different types of trichome. Nonglandular trichomes consisted of a basal cell and a long (up to ca. $300 \mu \mathrm{m}$ ) stalk. Meanwhile, capitate glandular trichomes had a secretory head and a short or long stalk. Peltate glandular trichomes with globose secretory heads were observed in close contact with the leaf epidermis. Spherical projections on the secretory head showed the secretion process of glandular trichomes. In addition to the trichomes, oval stomata were distributed on the abaxial leaf surface. These results suggest that ambient VP-FESEM can be used to classify the dehydration-sensitive foliar trichomes of succulent plants by SE imaging. At the FESEM resolution, this approach facilitates the rapid and detailed morphological analysis of a variety of trichomes in diverse plant taxa with reduced labor and preparation.

Key Words: Gland, Plectranthus tomentosa, Trichome, Variable pressure

\section{INTRODUCTION}

Scanning electron microscopy (SEM) has become an indispensable tool for visualizing the plant surface. A fundamental requirement of conventional SEM (CSEM) is the need for high-vacuum conditions throughout the column, typically around $10^{-3} \sim 10^{-5} \mathrm{~Pa}$, to minimize primary electron scattering (Stokes, 2008). This requirement necessitates a series of complex specimen preparation steps, including fixation, dehydration, drying, and metal coating, because specimens should be vacuum stable, vacuum friendly, and electrically conductive (Stabentheiner et al., 2010). The specimen preparations themselves can change the structural or chemical nature of the specimens, leading to the imaging of unwanted artifacts (Stokes, 2008).

Variable pressure SEM (VP-SEM) is often called environmental or low-vacuum SEM. It allows observations to be carried out in the presence of gas at pressures of ca. 2 Torr (300 Pa) in the specimen chamber (Mohan et al., 1998). With a differential pumping system, VP-SEM maintains a gas (typically water vapor) pressure in the specimen chamber, while the electron gun remains at high vacuum (McGregor \& Donald, 2010). The gas ions that are produced by the collisions with secondary electrons (SE) compensate for the negative charge on the surface of nonconductive specimens (Stabentheiner et al., 2010). These features suggests that VP-SEM is well suited to biological imaging, by offering topographic images with a remarkable depth of field, without

This work was supported by the Kyungpook National University Research Grant, 2012.

@ This is an open-access article distributed under the terms of the Creative Commons Attribution Non-Commercial License (http://creativecommons.org/licenses/by-nc/3.0) which permits unrestricted noncommercial use, distribution, and reproduction in any medium, provided the original work is properly cited.

Copyrights @ 2013 by Korean Society of Microscopy 


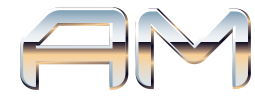

the need for specimen preparation or unwanted artifacts (McGregor \& Donald, 2010). Furthermore, the modern modality of field emission SEM (FESEM) equipped with VP abilities ensures the superb resolution and more versatile imagery than CSEM and FESEM.

The genus Plectranthus (Lamiales: Lamiaceae), also referred to as spurflowers, consists of ca. 300 species of evergreen perennials and subshrubs distributed through the tropical regions (Ascensão et al., 1999; Rice et al., 2011). With a diversity of ethnobotanical uses, the species of Plectranthus have been reported to produce monoterpenoids, sesquiterpenoids, diterpenoids, and phenolics (Lukhoba et al., 2006). As Plectranthus was the focused material of research activity at the Royal Botanical Gardens (Kew, UK), the genus from eastern and southern Africa was used as a model for defining a role for herbarium data in Red List assessments (Willis et al., 2003). In particular, the Vick's plant Plectranthus tomentosa is one of the most popular succulent herb plants. Although many Plectranthus species have been investigated because of their high content of essential oils, the leaf surface features have been reported only for a few species (Ascensão et al., 1999). As a plant surface sculpture, trichomes represent unicellular or multicellular appendages that develop outwards on the surface of various plant organs (Evert, 2006; Kim et al., 2011). Trichomes of Plectranthus and other genera have been observed by (i) CSEM after preparation process (Ascensão et al., 1998 and 1999; Bhatt et al., 2010) and (ii) VP-SEM without preparation (Kolb \& Müller, 2004; Stabentheiner et al., 2010). Backscattered electrons are usually detected for imaging in VP-SEM (Kim, 2008) and compositional contrast and reduced charging in CSEM (Kim et al., 2008), whereas SE have topographic relief for surface imaging. Recently, the trichomes of chili pepper were observed by detecting SE in VPFESEM (Kim et al., 2012); however, there are very few reports of SE imaging (SEI) by VP-FESEM. Detailed microscopic studies of the trichome profiles of $P$. tomentosa are demanded to further exploit the ornamental and pharmaceutical usability of the plant. Here, I use VP-FESEM to provide rapid and highresolution morphological profiling of the foliar trichomes of fresh $P$. tomentosa.

\section{MATERIALS AND METHODS}

\section{Plant Material}

A $10-\mathrm{cm}$-tall P. tomentosa plant was grown indoors in a pot under natural light. The plant had numerous trichomes on the leaf surface (Fig. 1). A peculiar aroma emanating from the plant could be detected even with a light touch. Fresh and fully developed leaves were collected from the plant for VPFESEM examination.

\section{Variable Pressure Secondary Electron Imaging}

Leaf segments (ca. $5 \times 5 \mathrm{~mm}^{2}$ ) were excised from the detached leaves using scissors. The specimens were readily mounted on a metal stub using the double-sided carbon tape (Kim, 2012). Without metal coating and cooling, they were directly examined with a Schottky type FESEM instrument (Supra 55VP, Carl Zeiss, Oberkochen, Germany) operated at an accelerating voltage of $15 \mathrm{kV}$. The SE signals were detected using a lateral below-lens VP SE detector under ca. $15 \mathrm{~Pa}$. Both the adaxial (upper) and abaxial (lower) leaf surfaces were observed with the electron microscope.

\section{RESULTS AND DISCUSSION}

VP-FESEM revealed that the leaf specimens were well preserved without severe collapse or charging effects (Fig. 2A). The adaxial surface of $P$. tomentosa leaf was covered with several types of trichome. Based on their shape, size, and secretion mode, foliar trichomes could be categorized into the following different groups. Nonglandular trichomes (NGT) were single, uniseriate, sharply pointed, and straight or curved in shape (Fig. 2B). NGT consisted of a basal cell and a long (up to ca. $300 \mu \mathrm{m}$ ) multicellular (five to seven cells) stalk. In some cases, minute globes were found on the terminal portion of the stalks (Fig. 2C). Approximately four epidermal cells were arranged around the base, forming a cellular pedestal to support the NGT.

In addition, two kinds of glandular trichomes (GT) were found on the leaf surface. (i) Capitate GT (CGT) had a secretory head and a short or long stalk (Fig. 2D). The secretory head was globose (ca. $50 \mu \mathrm{m}$ in diameter) and often possessed a spherical projection at its apex. (ii) Peltate GT (PGT) was characterized by a globose (ca. $20 \mu \mathrm{m}$ in diameter) secretory head and a very short stalk (almost sessile) on a basal cell

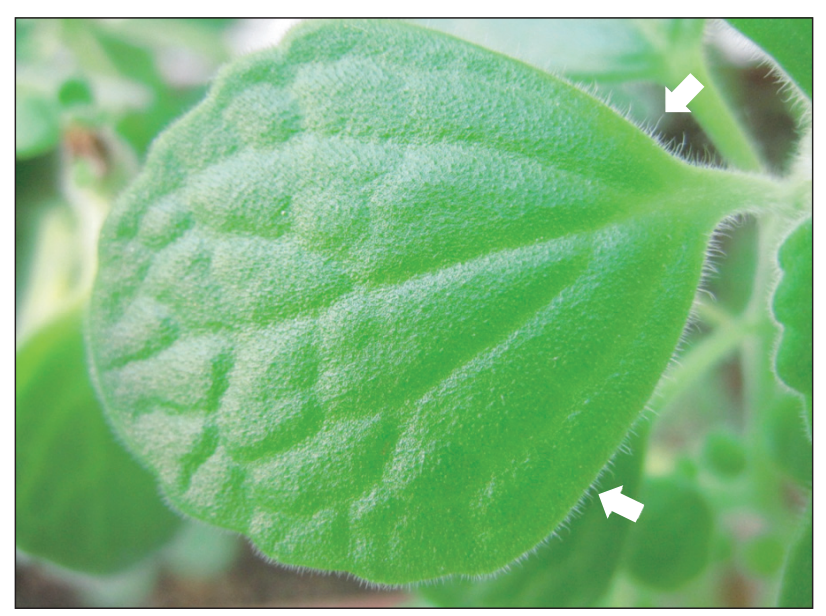

Fig. 1. A leaf of Plectranthus tomentosa. Trichomes (arrows) are discernible and prevalently distributed on the epidermis. 
(Fig. 2E). Collapsed PGT exhibited a slightly wrinkled surface on the secretory head. Some CGT consisted of a conelike secretory head and a short stalk (Fig. 2F). They possessed a minute spherical projection at their apex. No stomata were present on the adaxial leaf surface.

The abaxial leaf surface bore numerous NGT and GT on the
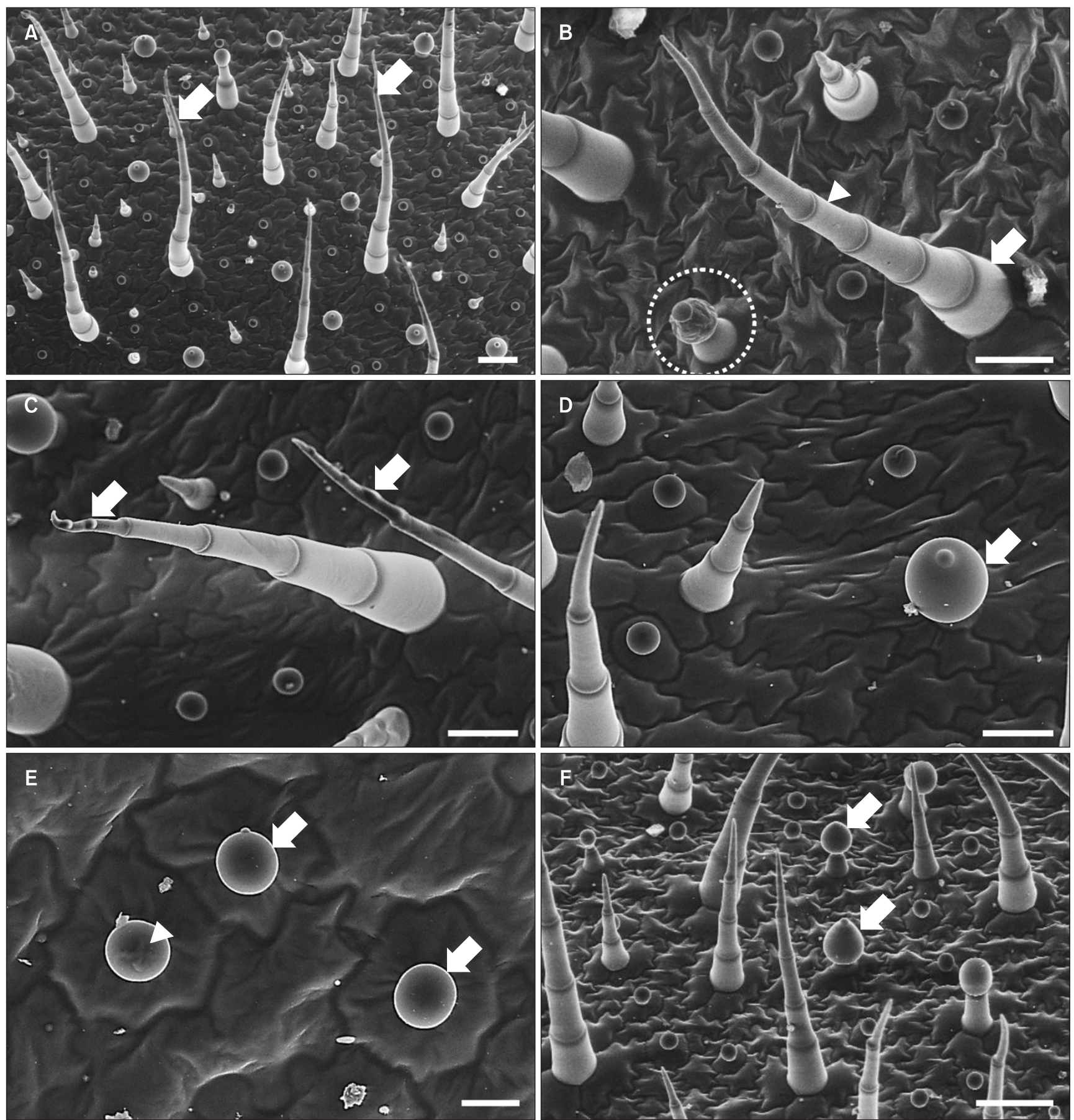

Fig. 2. Field emission scanning electron micrographs of the adaxial leaf surface of Plectranthus tomentosa. (A) Overall leaf surface. Nonglandular trichomes (NGT; arrows) are pointed and slightly curved in shape. Bar=100 $\mu \mathrm{m}$. (B) Higher magnification of an NGT. It has a basal cell (arrow) and a stalk (arrowhead). Long-stalked capitate glandular trichome (CGT) with a collapsed secretion head and a big secretion droplet is in a dotted circle. Bar=50 $\mu$ m. (C) Higher magnification of an NGT. It has minute globes (arrows) on the terminal cell of the stalks. Bar=50 $\mu \mathrm{m}$. (D) CGT (arrow). It has a spherical projection at its apex. Bar $=50 \mu \mathrm{m}$. (E) Peltate glandular trichomes (arrows). A wrinkled surface (arrowhead) is evident on the degenerative trichome. Bar=20 $\mu \mathrm{m}$. (F) CGT (arrows). They possess a conelike secretory head and a short stalk. Bar $=100 \mu \mathrm{m}$. 
leaf vein and the leaf lamina (Fig. 3A). NGT was characterized by a pointed, long, and slightly curved appearance (Fig. 3B). There was no morphological difference between NGT on the abaxial leaf surface and that on the adaxial leaf surface. CGT was also commonly found on the abaxial surface (Fig. 3C). As shown on the adaxial surface, a minute spherical
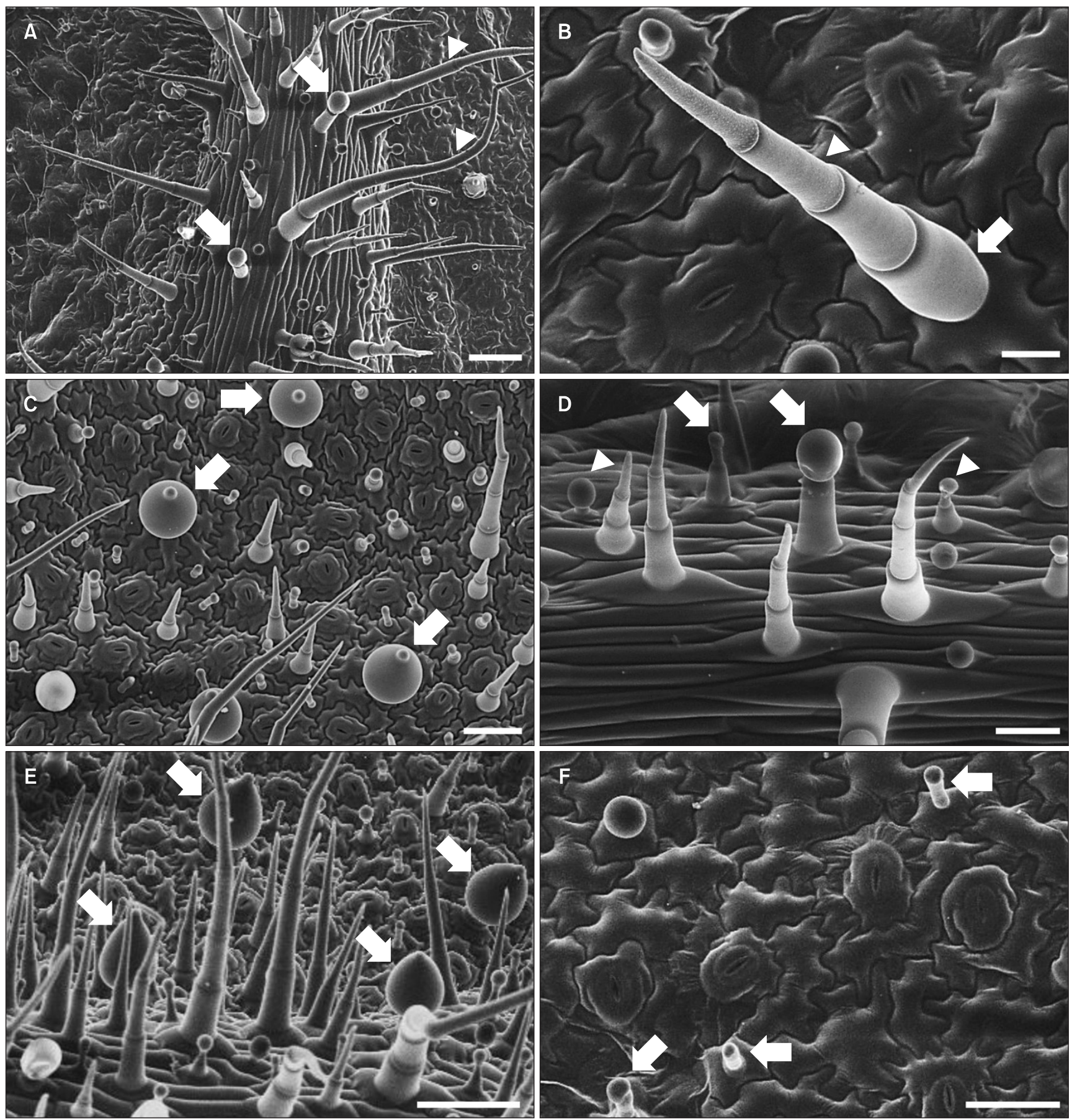

Fig. 3. Field emission scanning electron micrographs of the abaxial leaf surface of Plectranthus tomentosa. (A) Overall leaf surface. Both glandular trichomes (arrows) and nonglandular trichomes (NGT; arrowheads) are present on the leaf surface. Bar=100 $\mu$ m. (B) Higher magnification of an NGT. It comprises a basal cell (arrow) and a stalk (arrowhead). Bar=20 $\mu \mathrm{m}$. (C) Capitate glandular trichomes (CGT; arrows). They have a spherical projection at their apex. Bar=50 $\mu \mathrm{m}$. (D) CGT. Long-stalked CGT (arrows) have a bigger secretory head and a longer stalk than short-stalked ones (arrowheads). Bar=50 $\mu \mathrm{m}$. (E) CGT (arrows). They have a conelike secretory head and a short stalk. Bar=100 $\mu \mathrm{m}$. (F) Digitiform trichomes (arrows). They consist of several cells in line. Stomata are present on the abaxial leaf surface. Bar=50 $\mu \mathrm{m}$. 
projection was present at the apex of CGT. A tilted view revealed that CGT varied in stalk length (Fig. 3D). Longstalked CGT possessed a relatively large globose (ca. $50 \mu \mathrm{m}$ in diameter) secretory head and a relatively long (ca. $50 \mu \mathrm{m})$ stalk, whereas short-stalked CGT had a small globose (ca. 20 $\mu \mathrm{m}$ in diameter) secretory head and a short (less than ca. 20 $\mu \mathrm{m})$ stalk. CGT with a conelike secretory head and a short stalk was commonly observed (Fig. 3E). The secretory heads were ca. $50 \mu \mathrm{m}$ in diameter, and had a spherical projection at their apex. As another type, (iii) digitiform trichomes (DT) comprised several cells in line on the abaxial leaf surface (Fig. $3 \mathrm{~F}$ ). The glandular apical cells were rarely distinguished from the stalks. Numerous stomata were present on the abaxial leaf surface.

This study demonstrated the trichome profiling of $P$. tomentosa by VP-FESEM. Four types of trichome could be determined on the leaf surface: NGT, CGT, PGT, and DT (Fig. 4). Although DT was found only on the abaxial leaf surface, the other types of trichome occurred on both adaxial and abaxial leaf surfaces. It was evident that NGT with a long stalk was

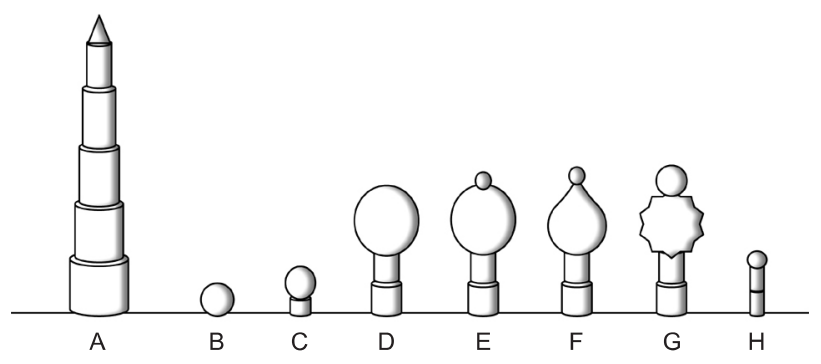

Fig. 4. Schematic diagram of foliar trichomes of Plectranthus tomentosa. (A) Nonglandular trichome. (B) Peltate glandular trichome. (C) Shortstalked capitate glandular trichome (CGT). (D) Long-stalked CGT. (E) Long-stalked CGT at the early secretion stage with a small secretion droplet. (F) CGT at the early secretion stage with a conelike secretion head and a small secretion droplet. (G) Long-stalked CGT at the active secretion stage with a collapsed secretion head and a big secretion droplet. (H) Digitiform trichome. mostly responsible for the hairy surface of the leaf (Fig. 4A). The most striking difference between PGT and CGT was the stalk height (Fig. 4B to 4D). As it is almost sessile, PGT is likely to have a collapsed secretion head.

An intriguing finding was that several distinct secretion stages could be determined by VP-FESEM based on the morphology of the secretion droplets on CGT. The spherical projections on CGT were strikingly similar to the secretion droplets on CGT of Cucurbita under VP conditions (Fig. 4E and F) (Kolb \& Müller, 2004). This implies that the CGT of P. tomentosa was under the early stage of secretory process. It is possible that the degenerated secretion head represents the active stage of the secretory process (Fig. 2B and 4G). Given the unrivaled capabilities of VP-FESEM as described above, the minute globes on NGT were assumed to be secretion droplets derived from neighboring CGT, as suggested from the CGT of other plants observed by VP-SEM (Kolb \& Müller, 2004; Sarria et al., 2010). DT could not be reasonably considered GT, in the absence of any report on the secretion process from the apical cell (Fig. 4H) (Ascensão et al., 1999).

\section{CONCLUSIONS}

VP-FESEM enabled the observation of dehydration-sensitive trichomes in their near-native state by SEI. Due to the direct specimen observations at the FESEM resolution, this approach facilitates the rapid and detailed morphological analysis of a variety of trichomes in diverse plant taxa with reduced labor and preparation.

\section{ACKNOWLEDGMENTS}

I am grateful to Sue Jin Jang, Saeng Geul Baek, Geun Ae Jang, and So Hee Kwon for electron microscopy in the National Instrumentation Center for Environmental Management at Seoul National University, Korea.

\section{REFERENCES}

Ascensão L, Figueiredo A C, Barroso J G, Pedro L G, Schripsema J, Deans S G, and Scheffer J C (1998) Plectranthus madagascariensis: morphology of the glandular trichomes, essential oil composition, and its biological activity. Int. J. Plant Sci. 159, 31-38.

Ascensão L, Mota L, and Castro M de M (1999) Glandular trichomes on the leaves and flowers of Plectranthus ornatus: morphology, distribution and histochemistry. Ann. Bot. 84, 437-447.

Bhatt A, Naidoo Y, and Nicholas A (2010) The foliar trichomes of Plectranthus laxiflorus Benth [Lamiaceae]: an important medicinal plant. New Zea. J. Bot. 48, 55-61.

Evert R F (2006) Esau's Plant Anatomy: Meristems, Cells, and Tissues of the Plant Body-Their Structure, Function, and Development (John Wiley and Sons, New Jersey).

Kim H J, Seo E, Kim J H, Cheong H, Kang B C, and Choi D (2012) Morphological classification of trichomes associated with possible biotic stress resistance in the genus Capsicum. Plant Pathol. J. 28, 107-113.

Kim I S (2012) Anatomical and morphological features of seeds in Portulaca. Appl. Microsc. 42, 194-199.

Kim K W (2008) Visualization of micromorphology of leaf epicuticular waxes of the rubber tree Ficus elastica by electron microscopy. Micron 39, 976-984. 
Kim K W, Cho D H, and Kim P G (2011) Morphology of foliar trichomes of the Chinese cork oak Quercus variabilis by electron microscopy and three-dimensional surface profiling. Microsc. Microanal. 17, 461468.

Kim K W, Choi S J, and Moon T W (2008) Backscattered electron imaging for reduced charging of moisturized corn starch granules: Implications for versatile imagery of hygroscopic powder specimens. Micron 39, 1160-1165.

Kolb D and Müller M (2004) Light, conventional and environmental scanning electron microscopy of the trichomes of Cucurbita pepo subsp. pepo var. styriaca and histochemistry of glandular secretory products. Ann. Bot. 94, 515-526.

Lukhoba C W, Simmonds M S J, and Patron A J (2006) Plectranthus: a review of ethnobotanical uses. J. Ethnobot. 103, 1-24.

McGregor J E and Donald A M (2010) ESEM imaging of dynamic biological processes: the closure of stomatal pores. J. Microsc. 239, 135-141.

Mohan A, Khanna N, Hwu J, and Joy D C (1998) Secondary electron imaging in the variable pressure scanning electron microscope. Scanning 20, 436-441.

Rice L J, Brits G J, Potgieter C J, and Van Staden J (2011) Plectranthus: A plant for the future? S. Afr. J. Bot. 77, 947-959.

Sarria E, Palomares-Rus F J, López-Sesé A I, Heredia A, and GómezGuillamón M L (2010) Role of leaf glandular trichomes of melon plants in deterrence of Aphis gossypii Glover. Plant Biol. 12, 503511.

Stabentheiner E, Zankel A, and Pölt P (2010) Environmental scanning electron microscopy (ESEM)-a versatile tool in studying plants. Protoplasma 246, 89-99.

Stokes D J (2008) Principles and Practice of Variable Pressure/ Environmental Scanning Electron Microscopy (VP-ESEM) (John Wiley and Sons, West Sussex).

Willis F, Moat J, and Paton A (2003) Defining a role for herbarium data in Red List assessments: a case study of Plectranthus from eastern and southern tropical Africa. Biodiv. Cons. 12, 1537-1552. 